\title{
EL PRIMER TRABAJO DEL HÉROE: HERAKLES DE WERNER HERZOG
}

\author{
Hero's First Labour: Werner Herzog's Herakles
}

Chantal Poch ${ }^{\mathrm{a}}$

Universidad Pompeu Fabra

DOI: $10.15366 /$ secuencias2021.53.002

\begin{abstract}
RESUMEN
La obra del cineasta bávaro Werner Herzog ha sido ampliamente estudiada; su primer cortometraje Herakles (1962), en cambio, ha merecido poca atención. Este artículo tratará de solventar ese vacío. Después de apuntar algunos vínculos personales de Herzog con el mundo clásico, exploraremos las características principales de Herakles como héroe para esbozar los motivos de su interés para el director. A continuación, analizaremos el contenido del cortometraje localizando en él los trabajos descritos en la Biblioteca de Apolodoro y fijándonos en su traslado a la contemporaneidad. Tras este análisis compararemos el Herakles que aparece en el film con los Herakles del péplum y algunos personajes posteriores del director para acabar definiendo una idea de forzudo particular de la filmografía de Herzog que entronca directamente con la propia visión de su carrera creativa.
\end{abstract}

Palabras clave: Werner Herzog, cortometraje, recepción clásica, cine alemán, Herakles.

\begin{abstract}
Bavarian filmmaker Werner Herzog's work has been widely studied; his first short film Herakles (1962), however, has received scarce attention. This paper aims to fill this gap. After focusing on Herzog's personal connections to the classical world, we will explore the main attributes of Herakles as a hero to come to terms with the director's interest in this mythical figure. We will continue with the analysis of the short's content, locating in it the labours described in Apollodorus' Library and examining their contemporary reconfiguration. We will proceed with the comparison of Herzog's Herakles with the peplum Herakles as well as with some of the filmmaker's later characters to conclude defining an idea of a particular strongman that appears throughout Herzog's filmography and that is directly related to his own vision of his creative career.
\end{abstract}

Keywords: Werner Herzog, short film, classical reception, German cinema, Herakles.

[a] Chantal Poch (Mataró, 1993). Doctora en Comunicación por la Universidad Pompeu Fabra con una tesis sobre el cine de Andrei Tarkovski, Werner Herzog y Terrence Malick. Graduada en Comunicación Audiovisual y Máster en Estudios de Cine y Audiovisual Contemporáneos por la misma universidad, durante el cual ejerce de asistente de docencia. Recientemente ha participado en el libro colectivo El cuerpo erótico de la actriz bajo los fascismos (Cátedra, 2018), ha publicado artículos académicos en L'Atalante y Open Cultural Studies, entre otros, y ha realizado una estancia en el Centro Studi ClassicA de la Universidad IUAV de Venecia. Combina su investigación con la actividad poética.

chantalpr@gmail.com 


\section{Introducción}

Muchas cosas se han escrito sobre la obra del cineasta Werner Herzog, pero pocas sobre su cortometraje Herakles, realizado en 1962. El corte que circula actualmente apenas dura doce minutos - se sabe que existe una anterior versión, no consultable. ${ }^{1}$ Cuando Herzog filmó Herakles, contaba con tan solo diecinueve años y nada de experiencia cinematográfica. Pese a estas circunstancias, Herakles no solo presenta unas decisiones estéticas suficientemente extravagantes como para prestarles atención, sino que plantea un diálogo especialmente interesante con la filmografía posterior del director dada su elección temática. Por ello, en este artículo nos centraremos en dos ideas indisociables de Herakles en la actualidad: la fuerza y lo clásico. En un primer apartado nos fijaremos en la constatable relación previa del director con los clásicos, tanto en lo que a formación se refiere como en lo personal. Presentaremos después brevemente los atributos dominantes de Herakles a lo largo de la historia y observaremos cómo algunos rasgos estéticos del cortometraje respaldan estos atributos. Tras detenernos trabajo por trabajo en el traslado de las descripciones de la Biblioteca de Apolodoro a imágenes contemporáneas, extraeremos algunas ideas alrededor de la fuerza que pondremos en diálogo con el resto de la filmografía de Herzog. Para concluir, plantearemos una extrapolación de lo estudiado a la carrera del director que nos permita acercarnos al significado de este primer cortometraje.

\section{Werner Herzog y los clásicos}

Cuando Herakles se estrena, Werner Herzog tan solo lleva un año estudiando literatura, historia y teatro en la Ludwig-Maximilians-Universität de Múnich, por lo que para entender el contexto de esta primera incursión en el cine necesitamos retroceder un poco más en el tiempo. Herzog, nacido Werner Stipetic en Sachrang, pasa su infancia en esta aldea y al crecer empieza el instituto en Heilbronn, cuando en 1953 se traslada con su madre a Múnich. Allí pasa a ser alumno de otro centro: el Maximiliansgymnasium, hasta 1961. No se trata de un dato anecdótico: «Estaba en el instituto en Múnich y la escuela tenía preferencia por lo clásico [had a classical bias]. Teníamos Latín y Griego Antiguo», cuenta él mismo. ${ }^{2}$ El Maximiliansgymnasium, todavía hoy abierto, presume de un énfasis humanístico claro: desde el quinto curso todos los alumnos estudian latín y, desde el octavo, griego antiguo. «No me gustaba la escuela, soy bastante autodidacta, nunca confié en la escuela, nunca confié en los maestros, pero algo se quedó ahí y solo después de la escuela, cuando ya hacía tiempo que la había terminado, empezó a gustarme. Empecé a leer, y por supuesto mi capacidad lectora en griego antiguo o latín está limitada por mi conocimiento del teatro griego, muy, muy, limitado. Mi conocimiento de la filosofía griega, bastante limitado. Evidentemente teníamos que leer a Platón en su original en la escuela, pero nunca tocó mi alma: eran otras cosas. Eran otras cosas las que me conmovieron y mantuvieron a mi mente comprometida hasta el día de hoy», declara Herzog. ${ }^{3}$ Tal fue el interés posterior del director en el griego antiguo que, según sus declaraciones, durante un tiempo de su vida fue capaz de mantener conversaciones en hexámetros con facilidad. ${ }^{4}$ Otra influencia primeriza fue de carácter familiar. En más de una ocasión Herzog habla de lo importante que fue su abuelo en su vida: Rudolph Herzog era arqueólogo y trabajó durante ocho años en la isla de Koos, donde encontró un Asklepeion - y donde más tarde Herzog rodaría Últimas palabras (Letzte Worte, 1968) y Signos de vida (Lebenszeichen, 1968). ${ }^{5}$
[1] Kraft Wetzel, «Interview with Werner Herzog», en Peter W. Jansen y Wolgram Schütte (eds.), Interviews: Herzog / Kluge / Straub (Múnich, Carl Hansen Verlag, 1976).

[2] John O'Rourke, «Filmmaker Werner Herzog to Reflect on his Career Tonight» (Boston University Today, 25 marzo 2019).

[3] Werner Herzog y Paul Höldengraber. Conversación. Onassis Encounters (Nueva York, 16 junio 2015).

[4] Werner Herzog y Paul Höldengraber. Conversación. Onassis Encounters (Atenas, 15 abril 2019).

[5] Werner Herzog y Paul Höldengraber. Conversación. Onassis Encounters (Nueva York, 16 junio 2015); Herzog, Werner y Paul Höldengraber. Conversación. Onassis Encounters (Atenas, 15 abril 2019). 
[6] Thomas Elssaesser, New German Cinema. A History (New Brunswick, New Jersey, Rutgers University Press, 1989).

[7] Werner Herzog, Lesson 21: Documentary. Eliciting Difficult Stories. Werner Herzog teaches filmmaking. Masterclass.com (2016).

[8] Steven Grossmith, "Steve Grossmith interviews Herbert Golder at Fusion International Film Festivals» (5 abril 2019).

[9] Werner Herzog, «On the Absolute, the Sublime, and Ecstatic Truth" (Arion: A Journal of Humanities and the Classics, vol. 17, n. $\left.{ }^{\circ} 3,2010\right)$, pp.1-12.

[10] Werner Herzog, «On Pope Benedict's Address to the Bundestag» (Arion: A Journal of Humanities and the Classics, vol. 19, n. $\left.{ }^{\circ} 3,2012\right)$, pp.1-2.

[11] Ver página web de la escuela: http://www.roguefilmschool.com/ about.asp

[12] Lexicon Iconographicum Mythologiae Classicae (LIMC) (Zúrich, Artemis, 1981-1999). Entrada «Herakles 728».
Inspirado por esta misma admiración Herzog viajó varias veces a Grecia durante su adolescencia, en una de ellas recorriendo toda la isla de Creta montado en un burro.

No solo los estudios sobre su obra han detectado la influencia de la cultura clásica en Herzog; ${ }^{6}$ el mismo cineasta asume la influencia que todo este fermento ha tenido en él. Refiriéndose a Fitzcarraldo (1982), hablará de su componente de Sísifo en varias ocasiones; respecto a El diamante blanco (The White Diamond, 2004), dirá que tras el hecho de preguntar al protagonista por la muerte de su mentor está la intuición de «algo de tragedia griega, una especie de castigo por haber querido volar». ${ }^{7}$ A finales de los años noventa Werner Herzog conoce a Herbert Golder, profesor de estudios clásicos en la Boston University, que en ese momento está explorando un caso real de matricidio. Herzog toma las riendas del proyecto y junto a Golder escribe lo que será My Son My Son What Have Ye Done (2010). Producida por otro admirador confeso de Herzog, David Lynch, la película narra cómo un hombre que en sus ratos libres ensaya la Orestíada de Esquilo junto a su grupo de teatro acaba llevando su papel protagonista a la vida real. El origen de este interés del bávaro en el proyecto está claro para Golder: «Cuando descubrí el trabajo de Werner me di cuenta: esto es tragedia griega. Si hoy Sófocles estuviera vivo, estas serían las películas que estaría haciendo». ${ }^{8}$

Golder, también editor jefe de Arion: A Journal for Humanities and the Classics, invitará a Herzog a publicar en un par de ocasiones desde su encuentro. Un primer texto consiste en la transcripción de una charla que el director dio sobre su concepto de verdad, donde se remite al origen etimológico de la palabra griega alétheia. ${ }^{9} \mathrm{Se}$ trata de un artículo ampliamente citado en los estudios sobre su obra, pues es una de las primeras ocasiones en la que se refiere a un tema que posteriormente ha marcado su recepción crítica. La otra publicación, en cambio, ha pasado completamente desapercibida. Resulta relevante para nosotros porque resume de manera clara su posición respecto a la importancia de la incorporación de la cultura clásica en la contemporánea. El breve texto, publicado en 2012 y titulado «On Pope Benedict's Adress to the Bundestag», solo pretende llamar la atención a los lectores de la revista sobre la profundidad de pensamiento que el autor detecta en dicho Papa, pero termina con una significativa afirmación: «El Papa Benedicto es fluente en latín y lee griego antiguo y hebreo bíblico, y su discurso está en la mejor tradición de los clásicos - aún más: cómo todavía sirven como principios guía para el Mundo Occidental». ${ }^{10}$ Los clásicos como principios-guía: eso mismo debió tener en mente cuando decidió que en su Rogue Film School la primera obra de su lista de lecturas obligatorias fuese Las Geórgicas de Virgilio. ${ }^{11}$

\section{El cuerpo del héroe}

La relación de Werner Herzog con la cultura clásica queda clara, pero ¿por qué empezar con Herakles? Aunque el director hable del corto como si hubiera sido poco más que una composición aleatoria, Herakles no es un personaje mitológico cualquiera. Su entrada en el LIMC registra: «El más fuerte de los héroes, se superó solo con su fuerza en lugar de con astucia o ayuda divina». ${ }^{12}$ Herakles es el héroe de lo físico, uno de los principales intereses temáticos de Herzog a lo largo de su carrera.

Varios autores clásicos destacan de Herakles su altura y corpulencia. Si es verdad que sus representaciones en la antigüedad van acompañadas a menudo de, por ejemplo, la piel del León de Nemea o un garrote, también lo es que ya desde el principio siempre aparecen delineados o esculpidos claramente sus pectorales o abdominales y 
que, poco a poco, su principal atributo pasa a ser su propio cuerpo. Sin duda es este cuerpo musculoso lo que ha travesado con mayor fuerza la imaginación de los artistas a lo largo de la historia. En la misma ciudad de Múnich el director podría haberse encontrado entre varias otras representaciones de Herakles desde una cabeza del siglo I en la Gliptoteca hasta una estatua barroca en el Schlosspark Nymphenburg. Separadas por siglos de diferencia, ambas obras comparten un especial énfasis en la robustez del héroe. En la estatua barroca, obra de Giuseppe Volpini, los muslos y antebrazos de Herakles se presentan enormes y adornados con varias capas de músculos mientras éste acaricia tranquilamente al león. De la obra romana solo queda la cabeza; pese a eso vemos un cuello grande y fuerte que anuncia el resto de su cuerpo como una mole. El paso del tiempo ha deteriorado la estatua, pero la extraordinaria fuerza de Herakles ha logrado permanecer.
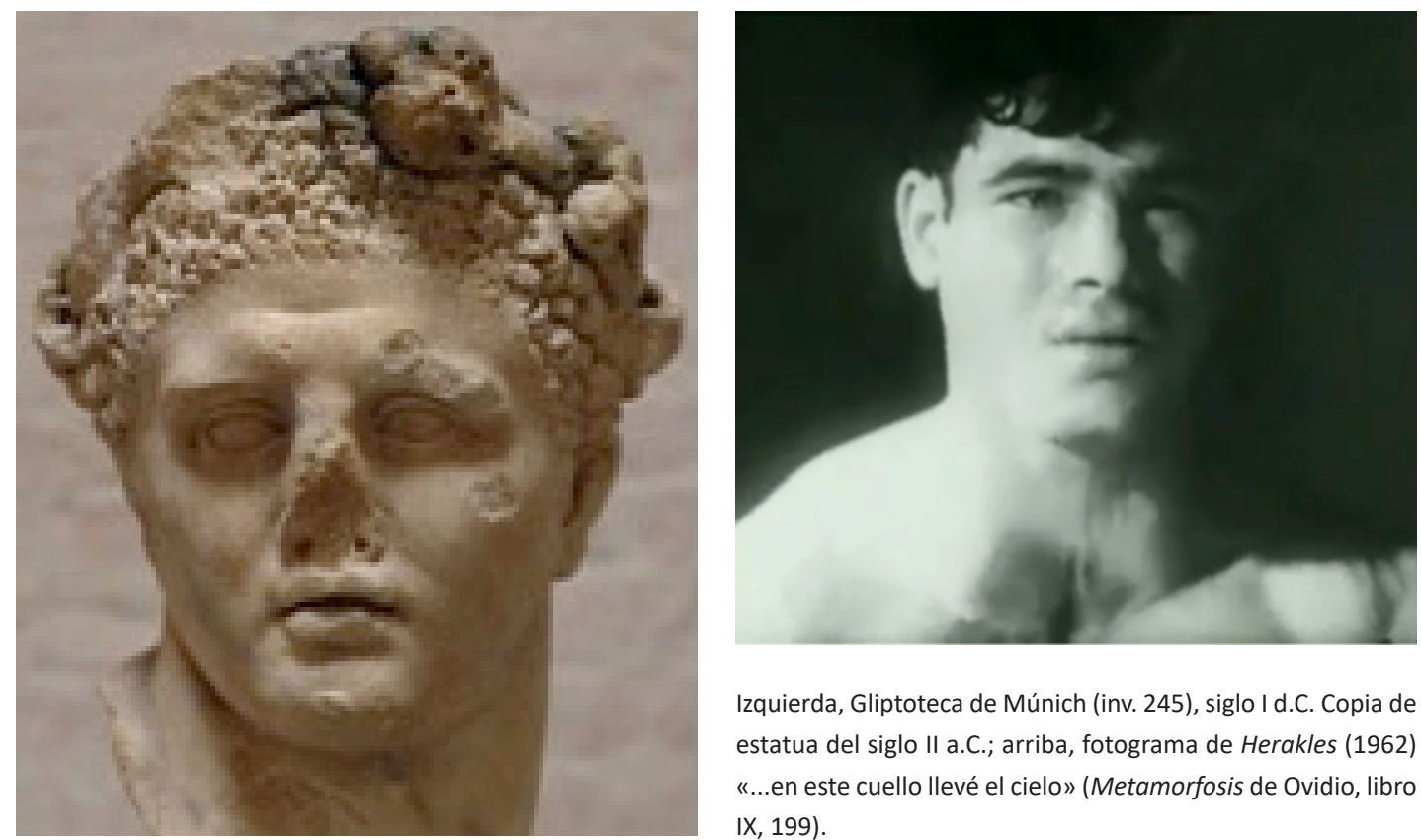

Izquierda, Gliptoteca de Múnich (inv. 245), siglo I d.C. Copia de estatua del siglo II a.C.; arriba, fotograma de Herakles (1962) «...en este cuello llevé el cielo» (Metamorfosis de Ovidio, libro IX, 199).

El cortometraje empieza con el detalle de un torso sobre el que aparecen los créditos iniciales. Se trata de un fragmento de cuerpo bien perfilado, con unos músculos imponentes: un juego de exposiciones lo muestra bien oscuro sobre un fondo blanco, como si de una silueta negra en un vaso de cerámica se tratara. Cuando acaban los créditos, un zoom out permite a la cámara mostrar la verdadera naturaleza de aquello que veíamos: no un cuerpo real, sino un póster delante del cual, ahora sí, un hombre real se ejercita en un gimnasio. Pesa en mano, sus ojos miran al vacío, concentrados. Y es que Herakles es, también, el héroe de los gimnasios. Uno de los emplazamientos más frecuentes de las estatuas en su honor en la Antigua Grecia eran estos verdaderos lugares de reunión, tal y como apunta Pausanias. ${ }^{13}$ En medio de su esfuerzo, los hombres podían ver al héroe y recordar sus hazañas; de un modo similar, el ser del cortometraje habita un espacio con imágenes de otros hombres que de alguna manera han pasado, también, a la inmortalidad, quedando plasmado su cuerpo en la pared.

El corto consiste en una serie de imágenes de los ejercicios de entreno de este

[13] Pausanias, Descripción de Grecia (Madrid, Gredos, 1984), sección 4.32.1. 
[14] Alastair Blanshard, Hercules: a Heroic Life (Londres, Granta Books, 2005), p.155. protagonista, de algunas de sus poses de exhibición y de las de otros culturistas, además de imágenes de archivo de otros eventos que por ahora dejaremos de lado. En la puesta en escena de este entrenamiento hay principalmente dos elecciones que llaman la atención. La primera tiene que ver con la composición: en su gran mayoría, los planos ofrecidos son medios, primeros y detalle. Este predominio es acompañado desde el principio por una preferencia por lo fragmentario: la cámara se acerca al cuerpo del culturista fijándose ahora en un brazo, ahora en la axila, ahora en sus abdominales. Vemos planos de músculos concretos flexionándose y contrayéndose en una imagen no muy habitual. La atención a estos relieves del cuerpo parece hacer hincapié en lo que en realidad estamos viendo; el culturismo consiste, al fin y al cabo, en modelar el cuerpo. Cada una de las líneas que vemos es producto del esculpir de este hombre en movimiento. La atención a los detalles de la musculatura es similar a aquella que los artistas griegos pusieron sobre las esculturas de Herakles; como nota Blanshard en su estudio, el Hércules Farnesio en particular ha tenido una gran influencia sobre el mundo del culturismo. ${ }^{14}$ Hecha para los baños de Caracalla en Roma en el 216 y actualmente en el Museo Arqueológico Nacional de Nápoles, el célebre Hércules Farnesio es en realidad una de muchas copias de un bronce original perdido del escultor griego Lisipo o su círculo, elaborada en torno al 330 a. C. La estatua muestra a Herakles/ Hércules reposando parte de su cuerpo apoyado en su garrote, con un pie avanzado y una mano ligeramente extendida mientras que en la otra guarda las manzanas del Jardín de las Hespérides. Aunque esté en un momento de reposo — popularmente se le ha conocido como Hércules cansado - , la posición semiflexionada que adopta permite mostrar la tensión de sus músculos, especialmente aquellos de los brazos, los muslos y el torso, muy curvado hacia la cadera. La comparación con otras estatuas masculinas de Lisipo, como Hermes atándose una sandalia, el Vertedor de aceite o el Apoxiómeno no deja duda: el cuerpo de Herakles supera en tamaño y fuerza tanto al de los atletas como al de los dioses. No estamos delante de un cuerpo que un hombre pueda conseguir solo con esfuerzo; debe buscarse tener ese cuerpo, centrarse en cada músculo. El cuerpo del Hércules Farnesio está formado por ingentes masas que luchan entre ellas; las mismas que vemos moverse en el cuerpo del Herakles de Herzog, la tensión de las cuales es subrayada por una iluminación que tiende al claroscuro.

El otro elemento de puesta en escena que destaca por su evidencia incumbe a lo que podríamos llamar el ritmo del cortometraje. Los planos son cortos y en varias ocasiones las imágenes se intercalan de manera que volvemos varias veces a la misma acción desde otra, por ejemplo: vemos una pesa girando, un brazo flexionándose, una pesa girando, un brazo flexionándose. Además, cada una de estas imágenes muestra un breve movimiento, de forma que una al lado de la otra genera
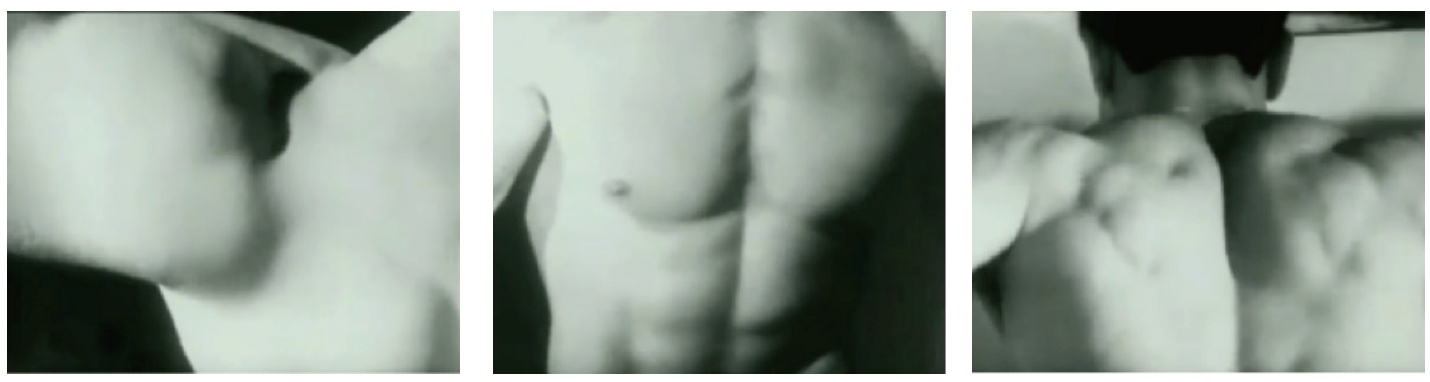

Fotogramas de Herakles. 
una cadena de ejercicios de ritmo constante. Tanto los efectos sonoros metálicos y estridentes como el hecho de que la cámara se acerque varias veces a los engranajes de cada aparato aumentan la sensación de estar delante no de un cuerpo humano sino de una pieza que participa en una maquinaria. Esta atención al engranaje, a la parte pequeña y el movimiento repetido e intenso, es la misma que se repetirá en la secuencia del barco de Fitzcarraldo décadas después. Pero mientras que allí estos engranajes se funden en una estética de árboles y barro, de paisaje natural, aquí estamos delante de un espacio cerrado, blanco, frío. Hay algo de artificial en la visión herzogiana del culturismo.

\section{Los trabajos}

A lo largo del cortometraje, en seis momentos la imagen se congela para mostrar un texto en pantalla. Se trata de seis preguntas, tras la aparición de cada una de las cuales entran en escena imágenes ya no de culturismo, sino de otros eventos que no ha filmado el propio Herzog. Los eventos se mezclan e intercalan con los ejercicios del protagonista y la exhibición de poses de otros hombres del mismo modo en que lo hacen el resto de las imágenes. Cada una de estas interrogaciones alude a alguno de los trabajos de Herakles y la relaciona solo a partir del montaje yuxtapuesto con filmaciones de archivo modernas. La historia de los trabajos de Herakles ha llegado hasta hoy influenciando a pintores, escritores, cineastas y hasta diseñadores de videojuegos en gran medida. Cuando Herakles asesina a su familia por culpa de la locura al que Hera le ha condenado - recordemos

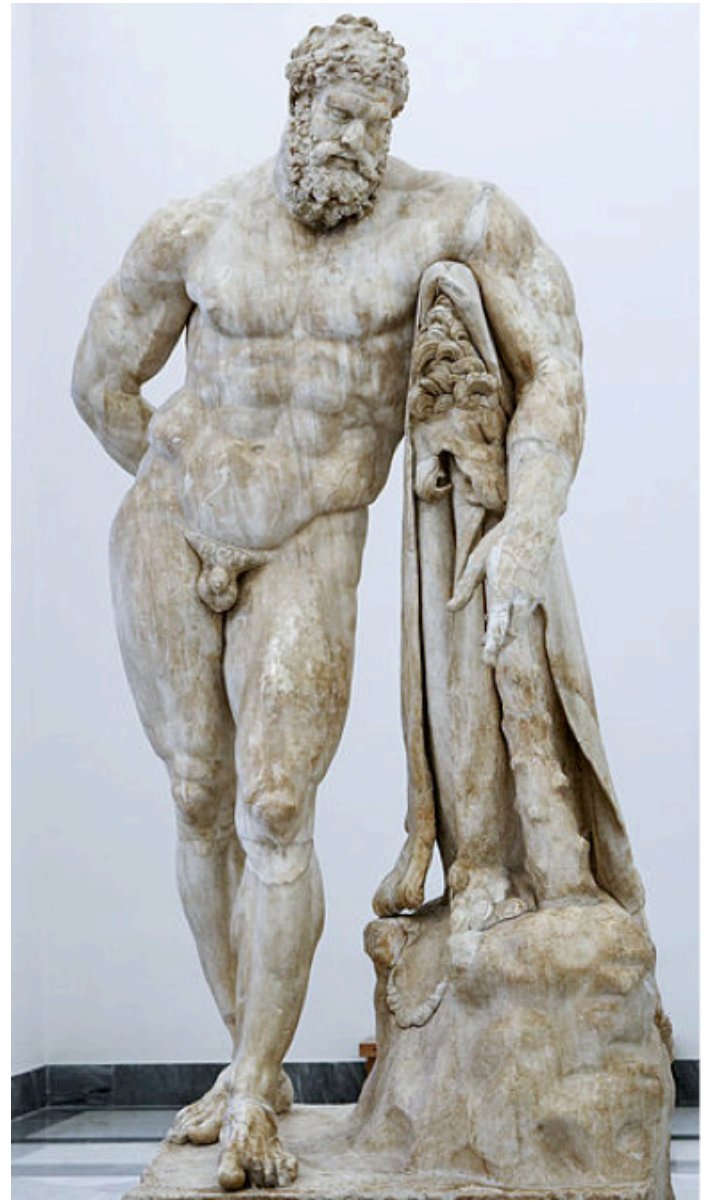

Hércules Farnesio. Glykon de Atenas, siglo III d. C. Copia de un bronce de Lisipo, siglo IV a. C. Museo arqueológico nacional de Nápoles (inv. 6001). que el héroe es producto de una de las muchas infidelidades de Zeus - se marcha a expiar sus pecados al servicio de Eristeo. Este le encarga los famosos trabajos, tras los cuales se hará inmortal.

La primera pregunta que aparece en pantalla versa «¿Limpiará el establo de Augías?» [Wird er den Augiasstall säubern?]. Según la narración que de la leyenda da Apolodoro en su Biblioteca — de ahora en adelante usaremos esta misma obra como referencia, por la extensión con la que trata el tema-,

Como quinto trabajo Euristeo le ordenó sacar en un día el estiércol del ganado de Augías. Éste era rey de Élide, hijo de Helios según unos, según otros de Posidón, y según otros aun de Forbante, y poseía muchos rebaños de ganado. Herakles se presentó a él y sin revelarle la orden de Euristeo le dijo que sacaría el estiércol en un solo día a cambio de la décima parte del ganado. Augías, aunque incrédulo, aceptó el trato; Herakles, puesto por testigo Fileo, el hijo de Augías, abrió una brecha en los cimientos del establo y desviando el curso del Alfeo y el Peneo, que discurrían cercanos, los encauzó hacia allí e hizo otra abertura como desagüe. ${ }^{15}$
[15] Apolodoro, Biblioteca (Madrid, Gredos, 1985), sección 2.5.5. Trad. Margarita Rodríguez de Sepúlveda. 
La interpretación en el corto del trabajo sucede así: la interrogación detiene una imagen frontal de Herakles cogiéndose las manos tras la espalda para sacar los pectorales con fuerza. Travelling de derecha a izquierda de un basurero que acaba en una zona donde se acumulan cajas de cartón; un hombre se ocupa de tirar aquellas que han quedado separadas más hacia las otras. El héroe balancea su torso con mirada concentrada, la cámara se acerca a sus pectorales y abdominales. Un gorro y unos guantes tirados por el suelo; un movimiento brusco deja aparecer la imagen de una enorme montaña de basura. Como en el establo de Augías, la basura se acumula infinitamente. El héroe practica una pose delante del espejo; a su espalda vemos a su modelo en un póster marcando una posición exagerada. Detalle del bíceps del protagonista. El protagonista haciendo pesas. Nadie acaba con la suciedad del basurero.
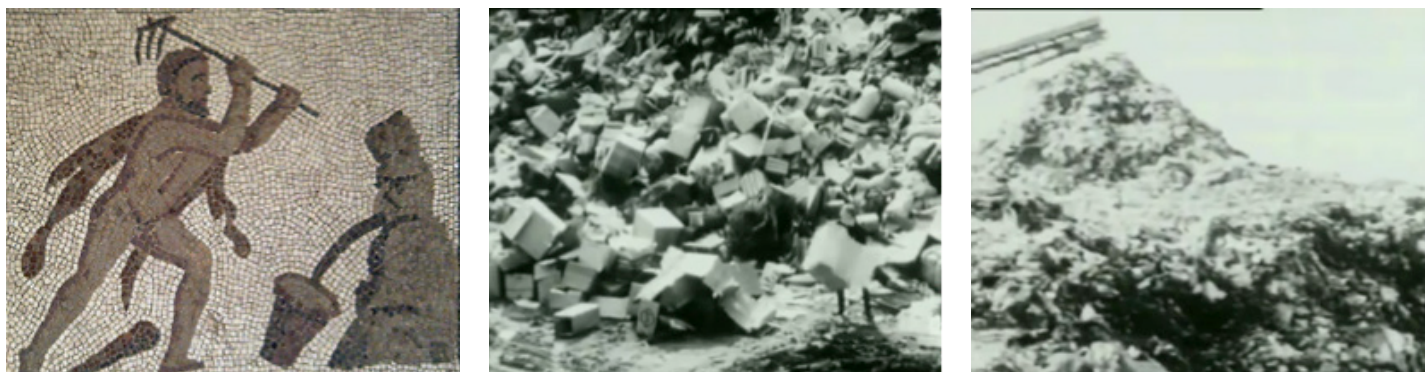

Izquierda, siglo III d. C., Valencia. Museo Arqueológico Nacional; centro y derecha, fotogramas de Herakles.

A continuación, pasamos a un espacio distinto, un escenario sobre el que un hombre totalmente cubierto de aceite exhibe sus músculos delante de un telón. Otro hombre realiza una posición distinta y su imagen se detiene con los brazos plegados sobre su pecho. «¿Matará la serpiente de Lerna?» [Wird er die lernäische Schlange töten?], pregunta el texto. Vemos una fila de coches formando una serpiente a lo largo de una carretera. Algunos conductores bajan de sus coches. Un culturista muestra el movimiento de sus omoplatos y tensiona los brazos hacia arriba. Una placa en la carretera muestra que se trata del quilómetro 138,5 mientras los coches siguen parados. El culturista flexiona los brazos, ahora hacia nosotros, y vuelve a plegarlos en su posición inicial. Un travelling a lo largo de la carretera muestra como la fila de coches detenidos se alarga hasta lo infinito. Veamos lo que Apolodoro recoge sobre este monstruo de Lerna:

[16] Apolodoro, Biblioteca, sección 2.5.2
Como segundo trabajo le ordenó matar a la Hidra de Lerna. Ésta, criada en el pantano de Lerna, irrumpía en el llano y destruía el campo y los ganados. La Hidra tenía un cuerpo enorme, con nueve cabezas, ocho mortales y la del centro inmortal. Herakles, montado en un carro que guiaba Yolao, llegó a Lerna y refrenó los caballos; al descubrir la Hidra en una colina, junto a la fuente de Amimone donde tenía su madriguera, la obligó a salir arrojándole flechas encendidas, y una vez fuera la apresó y dominó, aunque ella se mantuvo enroscada en una de sus piernas. De nada servía golpear las cabezas con la maza, pues cuando aplastaba una surgían dos. Un enorme cangrejo favorecía a la Hidra mordiendo el pie de Herakles. Él lo mató y luego pidió ayuda a Yolao, quien, después de incendiar parte de un bosque cercano, con los tizones quemó los cuellos de las cabezas e impidió que resurgieran. Evitada así su proliferación cortó la cabeza inmortal, la enterró y le puso encima una pesada roca, cerca del camino que a través de Lerna conduce a Eleúnte. ${ }^{16}$ 

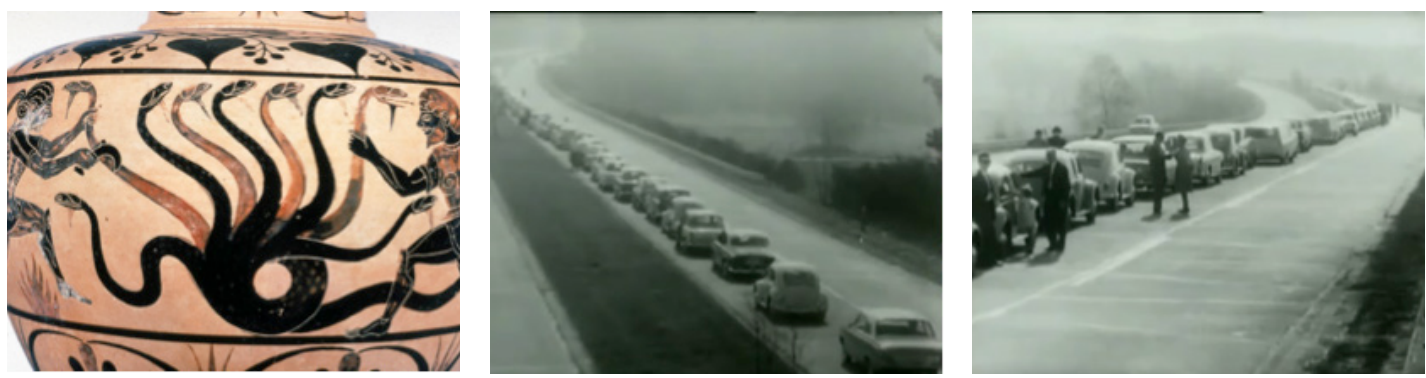

Izquierda, Circa 525 a. C., Etruria. J. Paul Getty Museum (inv. 83.AE.346); centro y derecha, fotogramas de Herakles.

La serpiente de coches tiene la misma habilidad que la Hidra; con el movimiento de cámara hacia el horizonte se recrea un efecto de multiplicación por el que las nuevas cabezas no dejan de aparecer. Pero aquí ningún Yolao aparece en ayuda de Herakles: su compañero estaba, igual que él, ocupado con su exhibición. En lugar de acabar con la Hidra, el héroe hace pesas apoyado en una plancha y ataviado con un slip.

Repite el ejercicio bocabajo, y luego la cámara se fija solo en su cabeza. Otra vez bocarriba; su cara de esfuerzo resoplando se detiene con el texto «¿Dominará a los caballos de Diomedes?» [Wird er die Rosse den Diomedes bezähmen?]. Narra Apolodoro,

Como octavo trabajo le ordenó llevar a Micenas las de Diomedes el tracio. Éste, hijo de Ares y Cirene, era rey de los bístones, pueblo tracio muy belicoso, y poseía yeguas antropófagas. Herakles zarpó con algunos voluntarios y, dominando a los guardianes de los pesebres, condujo a las yeguas en dirección al mar. Cuando los bístones acudieron armados a rescatar las yeguas, él las encomendó a la custodia de Abdero, hijo de Hermes, oriundo de Opunte, en Lócride, y favorito de Herakles; pero las yeguas lo mataron arrastrándolo. Herakles en combate con los bístones dio muerte a Diomedes y obligó a huir a los restantes; fundó la ciudad de Abdera junto al sepulcro del desaparecido Abdero, y reuniendo las yeguas las entregó a Euristeo. ${ }^{17}$

En lugar de ver caballos o yeguas, las imágenes muestran una carrera de coches. El héroe sigue levantando pesas y resoplando; los coches toman una curva, veloces. Un coche se destaca. El héroe, con las pesas. Otro coche choca con él y lo lanza por los aires. Las pesas. Varios coches vuelan por encima del público de la carrera causando explosiones a su caída. El público huye. Un policía intenta mantener el orden. El héroe levanta pesas. La gente llora, hay personas mutiladas esparcidas por el suelo. La gente

[17] Apolodoro, Biblioteca, sección 2.5.8
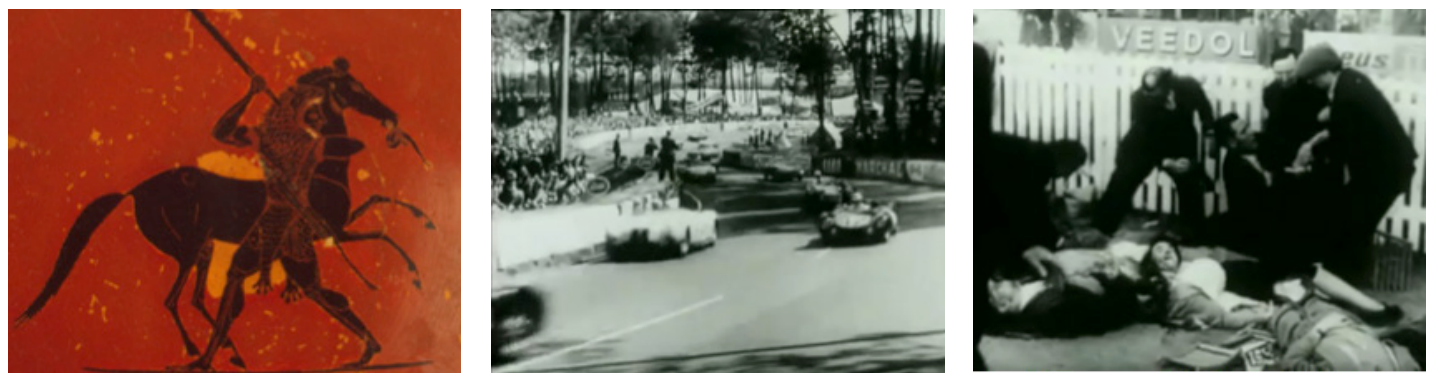

Izquierda, Circa 520 a. C., Ática. The State Hermitage Museum (inv. ГP-28190); centro y derecha, fotogramas de Herakles. 
carga cuerpos. Como las yeguas, los coches fueron usados al principio como transporte; luego se les enseñó por encima de sus posibilidades, llevando a escenas como la que vemos, pertenecientes al desastre de Le Mans 1955. El coche acaba devorando al propio piloto. Aquí Herakles tampoco interviene: marca posiciones frente al espejo. Mueve alternamente los pectorales. Levanta peso con los pies.

«Derrotará a las amazonas?» [Wird er die Amazonen besiegen?], se pregunta el siguiente texto mientras el protagonista fuerza un brazo. Un grupo de mujeres camina en formación. Visten un uniforme militar, y detrás de ellas el público queda debajo de unos telones coronados por banderas.

Como noveno trabajo ordenó a Herakles conseguir el cinturón de Hipólita. Ésta era la reina de las amazonas, que habitaban cerca del río Termodonte, pueblo sobresaliente en la guerra, pues practicaban las costumbres viriles [...]. Llegado al puerto de Temiscira, se presentó ante él Hipólita, le preguntó por qué había ido y le prometió entregarle el cinturón; pero Hera, bajo la apariencia de una de las amazonas, iba y venía entre la multitud diciendo que los extranjeros recién llegados habían raptado a su reina; así ellas cabalgaron con las armas hacia la nave. Cuando Herakles las vio armadas, creyendo que se trataba de un engaño, mató a Hipólita y la despojó del cinturón; después de pelear con las restantes se hizo a la mar y arribó a Troya. ${ }^{18}$

Las Amazonas que avanzan hacia un lado de la pantalla son, como las que describe Apolodoro, mujeres guerreras. Siguen avanzando sin problemas, pues Herakles está ocupado haciendo movimientos con sus pectorales y ejercitándose en todo tipo de máquinas.
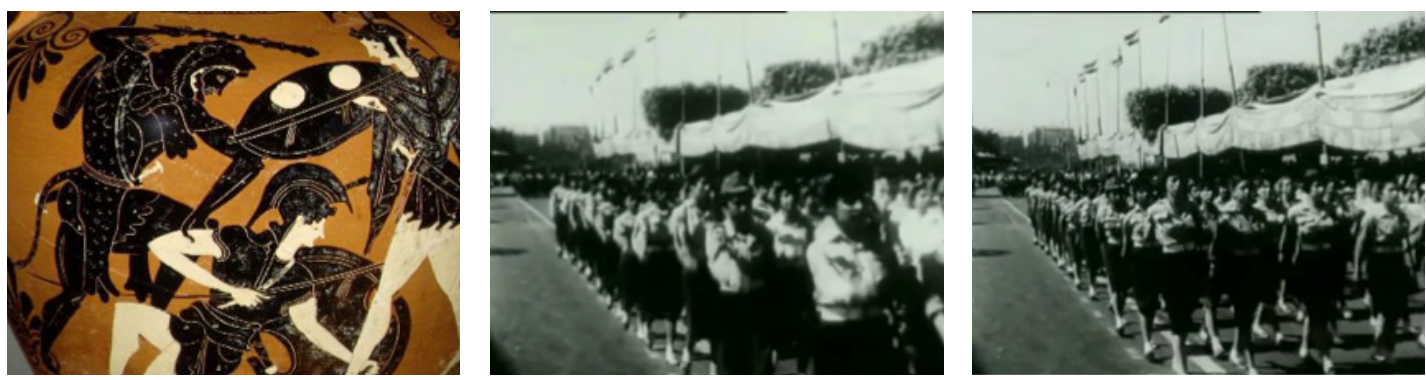

Izquierda, 510-500 a. C., Ática. Tampa Museum of Art (inv. 1982.11.1); centro y derecha, fotogramas de Herakles.

Volvemos al escenario de exhibición, donde dos hombres realizan diversos movimientos que acaban en antinaturales posiciones. Cuando uno de los dos contrae su pecho con las manos en las caderas y los codos hacia delante, sonriendo con esfuerzo, la pantalla pregunta: «Vencerá a los gigantes?» [Wird er die Giganten bezwingen?]. Aquí Herzog no está aludiendo a ninguno de los doce trabajos que Eristeo encarga a Herakles, sino al episodio de guerra entre gigantes y dioses que

[18] Apolodoro, Biblioteca. Trad. Margarita Rodríguez de Sepúlveda (Madrid: 1985). Sección 2.5.9

[19] Apolodoro, Biblioteca, sección 1.6.

[20] Apolodoro, Biblioteca, sección 1.6. sucede a la Titanomaquia, conocido como Gigantomaquia. «A los dioses se les había vaticinado que no podrían aniquilar a ningún gigante a menos que un mortal combatiera a su lado [...]», recoge Apolodoro. ${ }^{19}$ Así, los dioses se hacen ayudar por Herakles, que participa como mínimo en las muertes de Alcioneo, Porfirio y Efialtes, y que finalmente «remató con sus flechas a todos los moribundos». ${ }^{20}$ Esta vez no vemos en pantalla un símil de los gigantes en sí, sino de los efectos de tan salvaje guerra. Ruinas en medio de una ciudad; un caballo de juguete abandonado 
y un poste de electricidad abatido. Una vía del tren bajo la cual el suelo se ha desprendido totalmente. El culturista sigue con su torso contraído y flexiona uno de sus brazos. Un edificio desmoronado. La gente camina en todas direcciones y una furgoneta avanza hacia los escombros. Unos hombres trabajan rebuscando entre los restos de paredes y techos hechos trozos. El culturista levanta ambos brazos y flexiona orgulloso los bíceps. A un edificio le falta toda la fachada y aparece como una caja de cartón aplastada, como si los gigantes hubieran pasado por encima de ella; o la violencia de los dioses. Restos de una cama. Unos militares se llevan el cuerpo de una mujer.
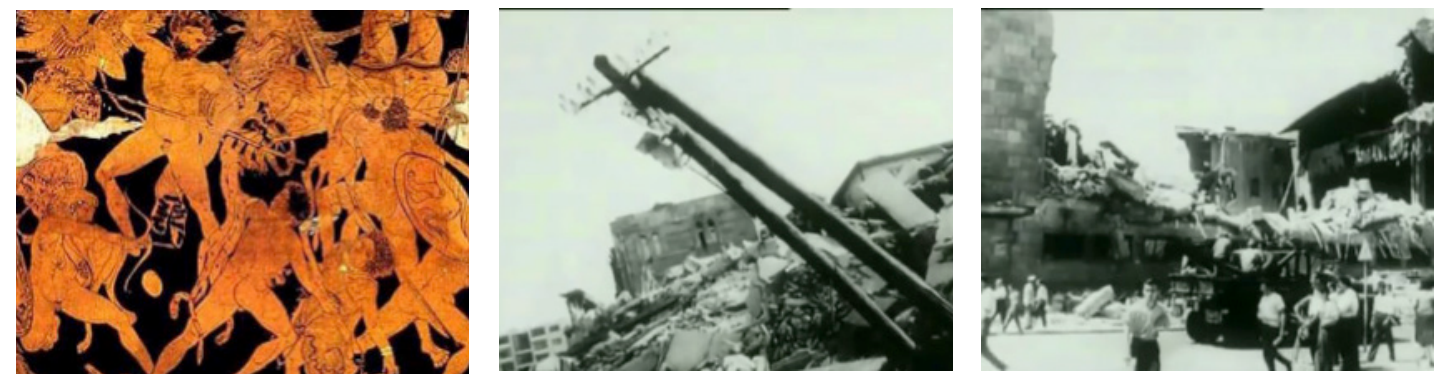

Izquierda, 410-400 a. C., Melos. Museo del Louvre (inv. MNB 810); centro y derecha, fotogramas de Herakles.

El héroe trabaja los músculos superiores de su espalda. Luego los de su cuello y antebrazos. Sus venas aparecen marcadas a través de la piel en tensión. «Resistirá a los pájaros del Estimfalo?» [Wird er sich der stingphalleschen Vögel erwehren?]. La cámara sigue la trayectoria de una formación de avionetas militares dejando humo tras de ellas. Son como las aves del Estínfalo, que Herakles tuvo que aplacar.

Como sexto trabajo le encargó ahuyentar las aves estinfálidas. En la ciudad de Estínfalo, en Arcadia, había un lago llamado Estinfalide, oculto por abundante vegetación, donde se habían refugiado innumerables aves, temerosas de ser presa de los lobos. Herakles no sabía cómo hacerlas salir de la espesura, pero Atenea le proporcionó unos crótalos de bronce, dádiva de Hefesto, y él entonces, haciéndolos sonar en una montaña próxima al lago, espantó a las aves, que incapaces de soportar el ruido alzaron el vuelo atemorizadas y de esta manera Herakles las flechó. $^{21}$

Otra avioneta es alcanzada por algún tipo de munición y explota en medio del cielo. El rostro de Herakles aparece un breve instante. Una furgoneta explota. El rostro de Herakles otra vez, Herakles moviendo la palanca de un aparato de pesas con expresión exhausta, detrás de él otro póster de un culturista. Una avioneta de la Fuerza Aérea Estadounidense deja caer un grupo de bombas. Las espaldas de Herakles se mueven hacia arriba y hacia abajo con el peso aplicado a la palanca. Las bombas caen, explotan, los árboles son dinamitados. Herakles de rodillas, levantando peso con el aparato. Bombas en un campo de pruebas. Herakles flexionando los brazos. Y bombas, y Herakles, y bombas, y Herakles.

Durante los últimos ejercicios de Herakles, la cámara se acerca a su rostro. Su boca se abre y cierra resoplando, sus ojos miran a un punto fijo sin inmutarse. Parece

[21] Apolodoro, Biblioteca, sección 2.5.6 

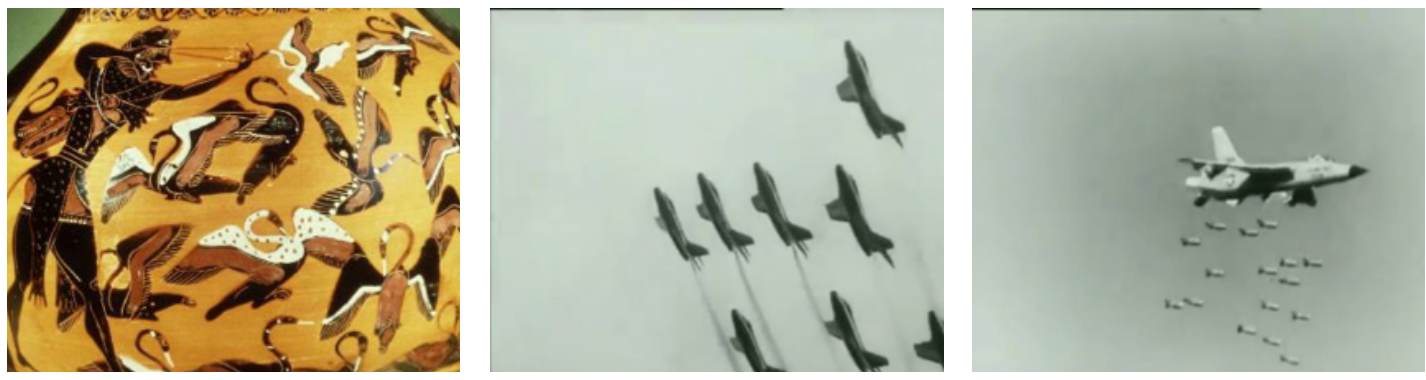

Izquierda, 560-530 a. C., Ática. British Museum (inv. B 163); centro y derecha, fotogramas de Herakles.

que no hay nada tras ellos. Aquellos ojos, que según el imaginario de varios autores griegos lanzaban miradas terribles e incluso fuego, ${ }^{22}$ sirven aquí solo para mirarse a sí mismo. La última imagen que, Herzog, burlón, decide incluir, es la del trasero del héroe en un slip blanco mientras se marcha a través del telón del escenario.

Hay una diferencia significativa entre las gestas a las que se hace alusión y aquellos eventos plasmados en pantalla. Las enormes pilas de basura, los atascos interminables, las formaciones militares aparecen por todo el mundo; no se trata de una hipérbole mitológica. Eristeo envía a Herakles a los establos de Augías porque son exageradamente sucios, no hay establos más difíciles de limpiar, de ahí la dificultad de la tarea; el basurero que vemos en las imágenes correspondientes a este trabajo, en cambio, no es ninguna excepción. Como este hay millones más. Tampoco hay tras la amenaza ningún autor. No están Augías, ni Diómedes, se trata de eventos de origen anónimo. Del mismo modo, no está Eritreo. Nadie ordena a Herakles hacer nada; y no existe nadie a quien enfrentarse. Están solo el héroe, las circunstancias, y su libre albedrío. Es en este libre albedrío donde se funda el espacio necesario para la pregunta. El Herakles de Ovidio, Homero y compañía no se preguntó nunca si sería capaz de llevar a cabo alguna misión. Aun siendo mitad hombre, mitad dios; aun habiendo sufrido como había sufrido por culpa de Hera, no se paró ante ningún trabajo. Porque creía en lo que hacía.

\section{Forzudos}

La respuesta a las preguntas que surgen a lo largo del corto y que, literal y metafóricamente, detienen la acción del héroe, está clara: no. Herakles no limpiará el establo de Augías, no matará a la serpiente de Lerna, no dominará a los caballos de Diomedes, no derrotará a las amazonas, no vencerá a los gigantes y no resistirá a los pájaros del Estínfalo. Está demasiado ocupado mejorando el aspecto de su cuerpo.

El actor que encarna a Herakles no es otro que Reinhard Lichtenberg, Míster Alemania 1962. Estamos hablando, pues, de un cuerpo que en teoría es visto como el ideal para todo un país. El mero acto de hacer de un culturista y míster el protago-

[22] Pind. Pae 20.13; Hom. Od. II, 608 .

[23] Daniel O’Brien, Classical Masculinity and the Spectacular Body on Film: The Mighty Sons of Hercules (Londres, Palgrave Macmillan, 2014). nista de su película remite a un género cinematográfico que hizo de esta una práctica habitual: el péplum. Definido a grandes rasgos como «una película de acción mitológica, histórico-mitológica o pseudo-mitológica, normalmente basada en leyendas greco-romanas, producida en Italia entre 1957 y 1965», ${ }^{23}$ el péplum aún está en boga cuando Herzog realiza su corto. Y el personaje mitológico que triunfó con más fuerza en el género fue, sin duda, Hércules. La película que con más éxito trató su historia 
fue Hércules (Le fatiche di Ercole, Pietro Francisci, 1958), que según algunos críticos fue precisamente la que sentó las bases del género. ${ }^{24}$ Como Lichtenberg, el actor protagonista de Hércules procede del mundo de la exhibición física: se trata de Steve Reeves, que tras ser Míster Universo y Míster Mundo en más de una ocasión triunfó de la mano de este tipo de películas entre mediados de los cincuenta y principios de los sesenta. En este filme vemos a un Steve Reeves de músculos brillantes en una serie de situaciones libremente basadas en la figura mitológica de Herakles que siempre implican la demostración de su descomunal fuerza. En el mismo inicio de la película Reeves arranca con las manos un árbol y lo lanza mientras corre hacia un carro que se conduce a un precipicio para frenarlo sin la menor dificultad; más tarde rompe con sus grandes brazos unas cadenas de hierro que lo mantienen prisionero.

El péplum plantea una perspectiva conservacionista de la mitología; las historias son trasladadas como hechos a la pantalla. Quizás por eso el género acabó agotándose en sí mismo; como si los clásicos cobrasen vida, poco conectaba las hazañas representadas con la contemporaneidad. Frank Burke resalta lo absurdo de estos films al describirlos como «hombres musculosos blandiendo rocas de papel maché». ${ }^{25} \mathrm{El}$ modesto cortometraje de Herzog trata de trazar esa relación con lo contemporáneo que en el péplum no existe $\mathrm{y}$, con esa voluntad, establece símiles de los trabajos de Herakles con situaciones más próximas al espectador del momento. Pero al pasar a la contemporaneidad, el cuerpo musculoso se vuelve impotente. Elsaesser dirá del corto que «más importante que enfrentar la imagen del superman con un mundo dominado por la tecnología es la misma posibilidad o imposibilidad de la revolución». ${ }^{26}$ Herakles estaría planteando, así, aquella misma cuestión a la que Herzog se enfrentará más adelante en su carrera con la realización de También los enanos empezaron pequeños (Auch Zwerge haben klein angefangen, 1970): ¿puede el hombre enfrentarse al mundo? Igual que en esta, la respuesta se juega a través de la corporalidad. Tanto los enanos como el culturista poseen cuerpos desproporcionados, manifiestamente fuera de la —o de una—normalidad. En También los enanos empezaron pequeños la estatura de los personajes no les permite ni tan siquiera llegar a la cama; en Herakles ni todos los músculos que con esfuerzo ha conseguido el protagonista sirven para luchar contra el mal. En ambos casos la traducción física de esta impotencia afecta también al entorno, pues los personajes de las dos películas se encuentran en espacios cerrados, limitando su percepción en diferentes medidas: el gimnasio y el hospital psiquiátrico.

Hay una constante en la mayoría de — las breves - lecturas que se han realizado sobre Herakles. Riley declara que «yuxtapone irónicamente el héroe mítico con un culturista contemporáneo»; ${ }^{27}$ De Pedro y Gómez resumen la intención del corto en «construir, mediante la contraposición, una burla de la inutilidad de la fuerza física extrema del hombre», ${ }^{28}$ y Wrigth afirma que «el espectador llega a reconocer la ironía del culturista impotente - una encarnación simbólica de Hércules, que sin embargo no tiene fuerza para conquistar ninguno de los trabajos míticos» ${ }^{29}$ Todos ellos identifican Francisci, 1958).
[24] Oscar Lapeña, «Pietro Francisci y el péplum», en Francisco José Salvador Ventura (ed.), Cine y autor: reflexiones sobre la teoría y la praxis de creadores filmicos (Santa Cruz de Tenerife, Intramar, 2011), p. 63.

[25] Frank Burke, «The Italian Sword-and-Sandal Film from Fabiola to Hercules and the Captive Women», en Flavia Brizio-Skov (ed.), Popular Italian Cinema. Culture and Politics in a Postwar Society (Londres, IB Tauris, 2011), p.17.
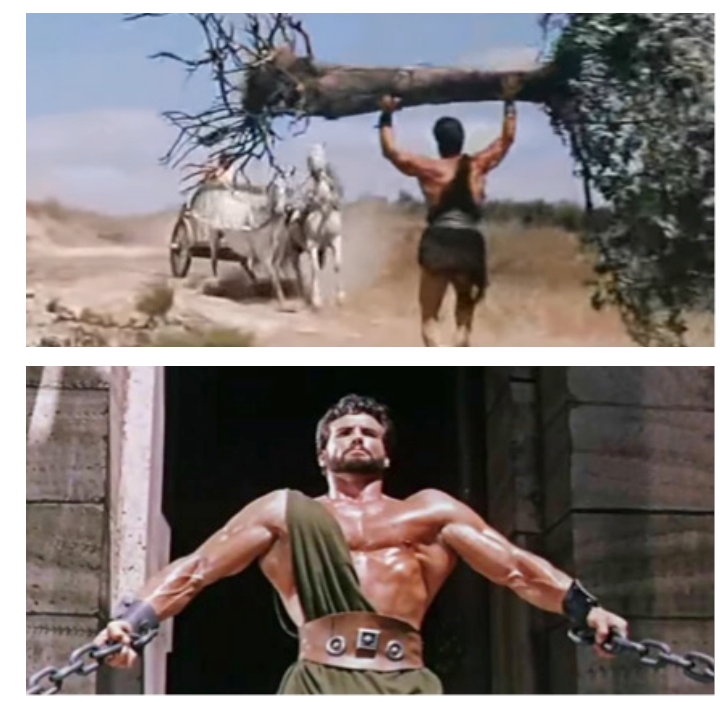

Fotogramas de la película Hércules (Le fatiche di Ercole, Pietro

[26] Thomas Elsaesser, New German Cinema. A History, p.222.

[27] Kathleen Riley, The Reception and Performance of Euripides'Herakles: Reasoning Madness (Oxford, Oxford University Press, 2008).

[28] Gonzalo de Pedro y Laura Gómez, «Filmando desde el volcán. El documental de Werner Herzog entre 1963 y 1978», en Carlos Losilla y José Enrique Monterde (eds.). Paisajes y figuras: perplejos. El nuevo cine alemán (1962-1982) (Valencia, Festival Internacional de Cine de Gijón y Ediciones de la Filmoteca, 2009). 
en el film una ironía desprendida de la impotencia del héroe, que aparece tan absurdo como si se dedicara a mover rocas de papel maché.

La verdadera pregunta que se forma entre estas imágenes se refiere a para qué está exactamente entrenando este culturista. No lo vemos llevando a cabo grandes hazañas, en lugar de eso vemos la imagen de un Narciso disfrutando del espectáculo de su propio físico. [...] El Hércules de esta película puede estar entrenando para salvar el mundo — ¿para qué, si no, estaría recubierto de músculos?—- pero está demasiado ocupado o absorbido en sí mismo para que le interesa nada aparte de él. ${ }^{30}$

Herakles llevó a cabo sus doce trabajos impulsado por el dolor y la culpa. El Herakles de Herzog aparece desconectado de sus misiones; los males del mundo parecen lejanos desde su gimnasio donde suena una alegre música jazz que tanto resalta la citada idea del libre albedrío (improvisación) como separa estéticamente el espacio cool del protagonista de las desgracias contemporáneas. Herzog nunca volverá a usar el jazz en otra película; progresivamente incorporará grandes piezas instrumentales o de voz coral - tanto clásicas como contemporáneas - a sus obras, siempre con cierta predilección por la grandilocuencia. El uso irónico de un tipo de música más cercana a lo popular quedará limitado a algunas excepciones como Teniente corrupto (Bad Lieutenant: Port of New Orleans, 2009).

Paralelamente su filmografía irá definiendo una heroicidad desde la creencia interior en una cosa. El cambio de banda sonora podría ser aquí significativo, pues ya no se trata de ironizar sino de revestir de importancia unos trabajos que han cobrado un significado distinto: si los hitos que se definen en Herakles serían sin duda útiles para el mundo, pero son irrealizables porque no han salido de él; ellos que en cambio se plantean personajes como Fitzcarraldo, Timothy Treadwell — Grizzly Man (2005) - o Graham Dorrington - El diamante blanco - son quizás no tan útiles para la humanidad, pero han brotado de una fuerte convicción interior y es por eso que aparecen con toda su heroicidad delante de nuestros ojos. En la mitología griega la épica no se encontraba en la fuerza de Herakles sino, precisamente, en su vulnerabilidad. No en una certeza de la victoria basada en sus cualidades físicas, sino en una certeza interior pese a lo absurdo que podían parecer sus trabajos. Tal y como Vollkommer estudia, la corpulencia de Herakles es tanto en el teatro como en la filosofía griega una metáfora de su fuerza de carácter. ${ }^{31}$

Para la reaparición literal de un forzudo en la filmografía de Herzog tendremos

[29] Cesare Wright, Re-Framing Ecstatic Truth. Experiments in the New Visual Language of Werner Herzog (Tesis Doctoral) (Nueva York, Universidad de Rochester, 2008) p. 159.

[30] Brad Prager, The Cinema of Werner Herzog: Aesthetic Ecstasy and Truth (Londres, Wallflower Press, 2007) p.21.

[31] Rainer Vollkommer, Herakles in the Art of Classical Greece (Oxford, Oxford University Committee for Archaeology, 1988) p.61-82. que esperar hasta 2001, cuando el director estrena Invencible (Invincible). La película se centra en la vida de Zishe Breitbart, un joven judío de extraordinaria fuerza que trabajó como forzudo de circo en la Alemania dominada por el nazismo. Reencontrando el sentido metafórico del mito que estudia Vollkommer, la corpulencia de Zishe no es más que la manifestación física de una rectitud de principios envidiable acompañada de cierta inocencia. "Para mí, "forzudo" es una palabra que reverbera más allá de las meras destrezas físicas. Implica fortaleza intelectual, independencia de criterio, confianza, autosuficiencia y tal vez, incluso, una especie de inocencia. [...] También tomo el recaudo de establecer una distinción entre forzudos y fisicoculturistas. Detesto el moderno culto del fisicoculturismo, me parece una desviación repugnante. Mi fascinación por los forzudos probablemente viene de los héroes de mi infancia en Sachrang», declara Herzog justo antes de recordar las leyendas que de pequeño había oído sobre el hombre que, al fallarle su mula, cargó él mismo los 
árboles sobre la espalda, o aquél que intentó volver un camión volcado a su sitio solo con las manos. ${ }^{32}$ El Herakles de Herzog no puede enfrentarse a sus trabajos porque está vacío por dentro; ni tan siquiera habla, porque no tiene nada que decir. Zishe, en cambio, saca su fuerza exterior de otro tipo de fuerza que se manifiesta en decisiones como enfrentarse verbalmente al público nazi de una de sus actuaciones y en su actitud protectora hacia aquellos a quienes ama.

\section{Conclusión}

A lo largo de estas páginas hemos examinado de qué manera Werner Herzog se acerca desde la contemporaneidad al mito de Herakles. Un examen de los atributos principales del héroe clásico y de la traducción de sus trabajos a imágenes contemporáneas nos ha ayudado a determinar el interés de este primer personaje en la filmografía del director, atravesada por fuerzas y forzudos. Tras estas observaciones estamos en posición de señalar el significado de Herakles en la carrera de Werner Herzog recuperando los apuntes sobre la relación con lo clásico que habíamos realizado en el primer apartado.

Aunque el director exprese un interés limitado en su primera obra, los apuntes que realiza sobre ella merecen nuestra atención: «Mi lección más inmediata y radical vino de la que fue mi primera pifia [blunder], Herakles», declara. ${ }^{33}$ Aun tachándola de error, Herzog reconoce el rol de Herakles en su aprendizaje. Más adelante en la misma entrevista, explica: «Los 35mm tenían la capacidad de demostrar, más que nada, si yo tenía o no algo que ofrecer, y cuando empecé pensé para mí mismo, "Si fracaso, fracasaré con tanta fuerza que nunca me recuperaré". Formaba parte de un grupo de jóvenes cineastas. Éramos unos ocho y la mayoría eran algo mayores que yo. De las ocho películas planeadas, cuatro nunca llegaron a producción, y otras tres fueron rodadas, pero nunca se completaron por problemas de sonido. El fracaso de los otros fue muy significativo: me enseñó que la organización y el compromiso eran las únicas cosas que empezaban y acababan películas, y no el dinero. En Fitzcarraldo, no fue el dinero el que empujó ese barco sobre la montaña, fue la fe». ${ }^{34}$ Hay algo de voluntad épica en esta manera de relatar el proceso: Herzog establece ya desde el principio un tono grandilocuente para el inicio de su carrera — «Si fracaso, fracasaré con tanta fuerza $[\ldots] »-$, y lo adorna con los fracasos de sus compañeros, que convierten su empresa en más improbable. Añadiendo Fitzcarraldo a la mezcla, convierte su propia figura de director en una imagen heroica: el barco subiendo por la montaña que, con permiso de Klaus Kinski, protagoniza esta película, aparece como la culminación de una serie de trabajos, empezando por Herakles, que el director ha tenido que superar con «organización y compromiso», con «fe». Para conseguir el poco dinero con el que realizó este «importante test», «aprendizaje», «ejercicio de edición», ${ }^{35}$ además, explica que trabajó como soldador por las noches. Sudor, esfuerzo, prueba y error: como el espacio donde transcurre, Herakles se convierte, a través de la posterior construcción que de él elabora Herzog, en el gimnasio donde el director se entrena para su posterior misión.

En este sentido Herakles aparece como la intuición de un joven director sobre su relación con el mundo; «aquí estoy yo, haciendo mis ejercicios de montaje mientras ahí fuera suceden cosas terribles», parece decir el corto. Pero con el tiempo Herzog desarrolla sus propias ideas sobre lo que ha de ser el director; no un fisicoculturista, sino un forzudo. Por un lado, sus películas no salvarán al mundo; por otro, tiene el deber de creer plenamente en ellas. El director debe levantar la película con sus propios
[32] Paul Cronin (ed.), Herzog on Herzog (Londres, Faber \& Faber, 2002) p. 32-33.

[33] Paul Cronin (ed.), Herzog on Herzog (Londres, Faber \& Faber, 2002) p. 32-33.

[34] Ibid., p. 12.

[35] Ibid. 
[36] Werner Herzog y Paul Höldengraber. Conversación. Onassis Encounters (Atenas, 15 abril 2019). brazos, por inútil que parezca realizarla. O precisamente porque es inútil realizarla. Quizás no represente una mejora para la humanidad, pero sí para el individuo, y al final en eso consiste ser un forzudo; en ser fuerte como individuo, en no ceder a las normas de los otros. No solo Herakles o Zishe Breitbart pueden leerse como forzudos: también lo serán Fini Straubinger —El país del silencio y la oscuridad (Land des Schweigens und der Dunkelheit, 1971) — cuando busque la manera comunicarse con el mundo y ayudar a otra gente sordociega, Kaspar Hauser - El enigma de Kaspar Hauser (Jeder für sich und Got gegen alle, 1974) — cuando un poco involuntariamente cuestione las normas que la sociedad le ofrece como «normales», como la mayoría de los protagonistas de Herzog.

También en el hecho de reivindicar la cultura clásica hay un extraño gesto de fuerza. «Creo que es desastroso, es un error desastroso que la mayoría de las universidades estén abandonando los departamentos de estudios clásicos. Es un error monumental, un error porque nos estamos robando el conocimiento y raíces de nuestra identidad cultural, un conocimiento profundo de qué somos y dónde estamos, y esto es un gran error porque claro que el estudio de la literatura antigua, o de la historia antigua no tiene un valor práctico. Cuando forman a un médico o a un físico o a un especialista en informática lo exprimen y está bien que lo hagan, pero al mismo tiempo para ahorrar dinero eliminan lo que es verdaderamente esencial». ${ }^{36}$ Conocer los clásicos, nos dice Herzog, nos ayuda a comprender qué somos y dónde estamos. El mundo necesita a Herakles precisamente porque cree no necesitarlo ya. Aceptar la propia impotencia es el primer paso para dejar de contemplar el propio cuerpo en el espejo y ponerlo a trabajar de verdad; verse pequeño en la historia es empezar a verse héroe. Admitir la vinculación con lo antiguo. Así, el primer cortometraje del director se convierte en su primer trabajo: aquel donde se compromete con su fuerza y reconoce sus debilidades.

\section{BIBLIOGRAFÍA}

Apolodoro, Biblioteca (Madrid, Gredos, 1985). Trad. Margarita Rodríguez de Sepúlveda.

Blanshard, Alastair, Hercules: a Heroic Life (Londres, Granta Books, 2005).

Burke, Frank, «The Italian Sword-and-Sandal Film from Fabiola to Hercules and the Captive Women», en Flavia Brizio-Skov (ed.), Popular Italian Cinema. Culture and Politics in a Postwar Society (Londres, IB Tauris, 2011).

Cronin, Paul (ed.), Herzog on Herzog (Londres, Faber \& Faber, 2002).

De PEDro, Gonzalo y Gómez, Laura, «Filmando desde el volcán. El documental de Werner Herzog entre 1963 y 1978», en Carlos Losilla y José Enrique Monterde (eds.) Paisajes y figuras: perplejos. El nuevo cine alemán (1962-1982) (Valencia, Festival Internacional de Cine de Gijón y Ediciones de la Filmoteca, 2009).

Elsaesser, Thomas, New German Cinema. A History (New Brunswick, New Jersey Rutgers University Press, 1989).

Grossmith, Steve, Steve Grossmith interviews Herbert Golder at Fusion International Film Festivals (5 abril 2019).

Herzog, Werner y Höldengraber, Paul, Conversación. Onassis Encounters (Nueva York, 16 junio 2015).

—, Conversación. Onassis Encounters (Atenas, 15 abril 2019). 
Herzog, Werner, «On Pope Benedict's Address to the Bundestag» (Arion: A Journal of Humanities and the Classics, vol. 19, núm. 3, 2012), pp.1-2.

—, Lesson 21: Documentary. Eliciting Difficult Stories. Werner Herzog teaches film making. Masterclass.com (2016).

LAPEÑa, Óscar, Pietro Francisci y el péplum, en Francisco José Salvador Ventura (ed.), Cine y autor: reflexiones sobre la teoría y la praxis de creadores filmicos (Santa Cruz de Tenerife, Intramar, 2011), pp. 59-75.

O'BRIEn, Daniel, Classical Masculinity and the Spectacular Body on Film: The Mighty Sons of Hercules (Nueva York, Palgrave MacMillan, 2014).

O'ROURKE, John, «Filmmaker Werner Herzog to Reflect on his Career Tonight» (Boston University Today, 25 de marzo 2019).

Pausanias, Descripción de Grecia (Madrid, Gredos, 1984).

Prager, Brad, The cinema of Werner Herzog: Aesthetic Ecstasy and Truth (Londres y Nueva York, Wallflower Press, 2007).

Riley, Kathleen, The Reception and Performance of Euripides' Herakles: Reasoning Madness (Oxford, Oxford University Press, 2008).

Vollkommer, Rainer, Herakles in the Art of Classical Greece (Oxford, Oxford University Committee for Archaeology 1988).

VvaA., Lexicon Iconographicum Mythologiae Classicae (LIMC) (Zúrich, Artemis, 1981-1999).

Wetzel, Kraft, «Interview with Werner Herzog», en Peter W. Jansen y Wolfram Schütte, (eds.) Interviews: Herzog / Kluge / Straub (Múnich, Carl Hansen Verlag, 1976).

Wright, Cesare, Re-Framing Ecstatic Truth. Experiments in the New Visual Language of Werner Herzog (Tesis doctoral) (Nueva York, Universidad de Rochester 2008).

Recibido: 19 de diciembre de 2019

Aceptado para revisión por pares: 24 de abril de 2020

Aceptado para publicación: 29 de agosto de 2020 